Groth, C. G., and Thoren, G. (1965). Acta Chirurgica Scandinavica, 130,

Langsjoen, P. H., and Inmon, T. W. (1968). Angiology, 19, 247

Mayer, G. A. (1964). Canadian Medical Association fournal, 91, 951.

Poiseuille, J. L. M. (1846). Comptes Rendus Hebdomadaires des Séances de l'Académie des Sciences, 9, 433.
Skovborg, F., Nielsen, A. V., Schlichtkrull, J., Ditzel, J. (1966). Lancet 1,129

Skovborg, F., Nielsen, A. V., and Schlichtkrull, J. (1968). Scandinavian Fournal of Clinical and Laboratory Investigation, 21, 83.

Wells, R. E. (1966). Bibliotheca Anatomica, 9, 520.

Yao, S. T., and Shoemaker, W. C. (1966). Annals of Surgery, 164, 973.

\title{
Glucagon in the Treatment of Paget's Disease of Bone
}

\author{
JOHN R. CONDON
}

British Medical fournal, 1971, 4, 719-721

\section{Summary}

Glucagon given by intravenous infusion at a dosage of 0.2 to $0.8 \mathrm{mg} / \mathrm{hour}$ to four patients with Paget's disease of bone resulted in a dramatic fall in plasma alkaline phosphatase. This was associated with a fall in 24-hour urinary calcium and in total urinary hydroxyproline excretion and a marked relief of bone pain.

Glucagon may induce these changes by three possible mechanisms: (1) by stimulating release of calcitonin; (2) by a direct action of the hormone on bone; and (3) by stimulation of certain bone pyrophosphatases, thus altering the local mechanisms controlling the rate of bone formation and resorption.

\section{Introduction}

Calcitonin has been reported to induce clinical and biochemical remission in patients with Paget's disease of bone (Bijvoet et al., 1968; Woodhouse et al., 1971). Glucagon might also be expected to be of benefit in this disorder since it stimulates release of calcitonin from the thyroid gland (Care et al., 1970a).

Clinical and biochemical results in four patients with Paget's disease of bone treated with glucagon are reported. The mode of action of the hormone in this disorder is discussed.

\section{Methods}

Total urinary hydroxyproline was measured by the method of Grant (1964) modified by Pennock et al. (1970). Plasma alkaline phosphatase was measured by the method of Kind and King (1954), plasma calcitonin (Dr. G. V. Foster) by a radioimmunoassay technique (Clark et al., 1969), urine calcium by flame spectrophotometry (MacIntyre, 1960), plasma calcium by EDTA titration (Gehrke et al., 1954), and plasma phosphate by the method of Kraml (1966).

Glucagon Therapy.-Glucagon was dissolved in $500 \mathrm{ml}$ of normal saline and administered by slow intravenous infusion. The rate of giving glucagon varied from 0.2 to $0.8 \mathrm{mg} /$ hour. In Cases 1 and $21 \mathrm{mg}$ was given intravenously as an initial dose; this was designed to stimulate release of calcitonin, which was assayed in these two patients.

\section{Case 1}

A 65-year-old man with bone pain had radiological evidence of extensive osteitis deformans. Plasma calcium was $9.4 \mathrm{mg} / 100 \mathrm{ml}$,

St. George's Hospital, London S.W.1

JOHN R. CONDON, B.SC., M.R.C.P., Senior Registrar plasma phosphate $3.9 \mathrm{mg} / 100 \mathrm{ml}$, and plasma alkaline phosphatase 109 King-Armstrong (K.A.) units $/ 100 \mathrm{ml}$.

Treatment with glucagon resulted in a dramatic fall in plasma alkaline phosphatase which was most pronounced on the fifth and sixth days (Fig. 1). It began rising slowly on the ninth, tenth, and eleventh days, this rise possibly being due to a reduction in the dose of glucagon given on the third and fourth days. Increasing glucagon dosage on the fifth and eighth days of treatment resulted in a further steep fall in plasma alkaline phosphatase to 56 K.A units $/ 100 \mathrm{ml}$. The total fall in plasma alkaline phosphatase was 52 K.A. units $/ 100 \mathrm{ml}$ during nine days of glucagon therapy. The

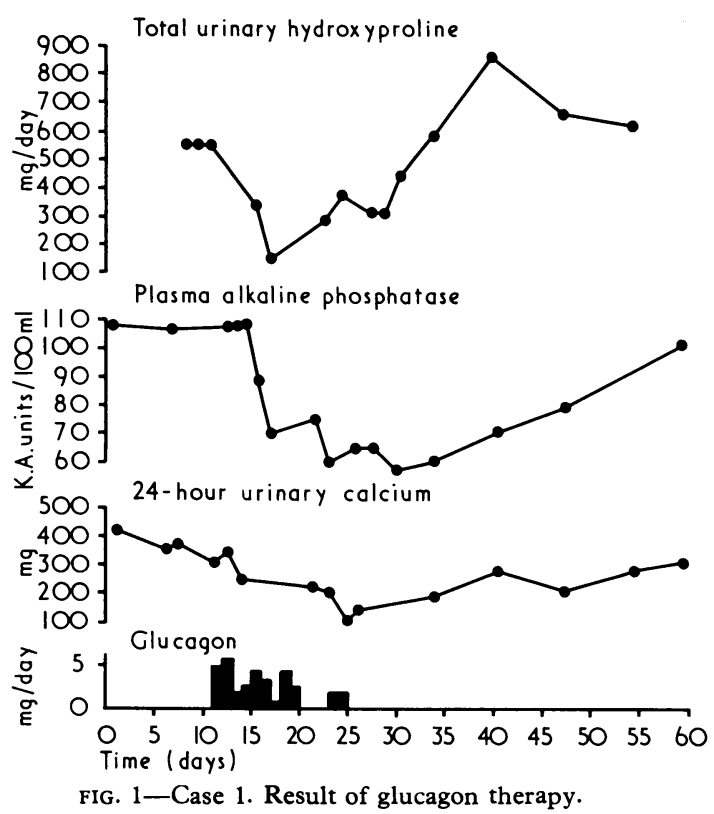

urinary calcium fell from a mean value of $379 \mathrm{mg} / 24$ hours before treatment to $78 \mathrm{mg} / 24$ hours. Total urinary hydroxyproline also fell during therapy. Plasma calcium values remained within normal limits during therapy but there was an intermittent fall in plasma phosphate to $3.3 \mathrm{mg} / 100 \mathrm{ml}$.

Relief of bone pain occurred six days after beginning treatment but when glucagon was stopped mild bone pain returned within 12 days and this became more severe 26 days after stopping glucagon. Recurrence of bone pain was accompanied by a rise in plasma alkaline phosphatase, total urinary hydroxyproline, and urinary calcium values, thus confirming that the clinical and biochemical changes noted were the result of glucagon therapy. Calcitonin was undetectable (less than $500 \mathrm{pg} / \mathrm{ml}$ ) in blood samples taken immediately before and at 15,30 , and 240 minutes after initial glucagon infusion.

\section{Case 2}

A 76-year-old woman with clinical and radiological evidence of Paget's disease of bone was also treated with glucagon. The plasma alkaline phosphatase fell from 160 to 64 K.A. units $/ 100 \mathrm{ml}$ within 


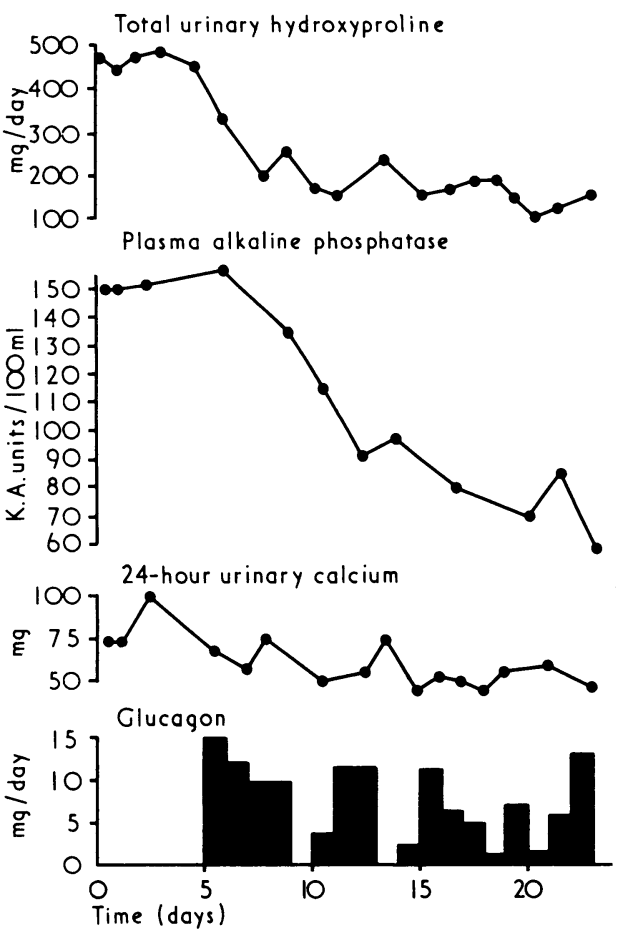

FIG. 2-Case 2. Results of glucagon therapy.

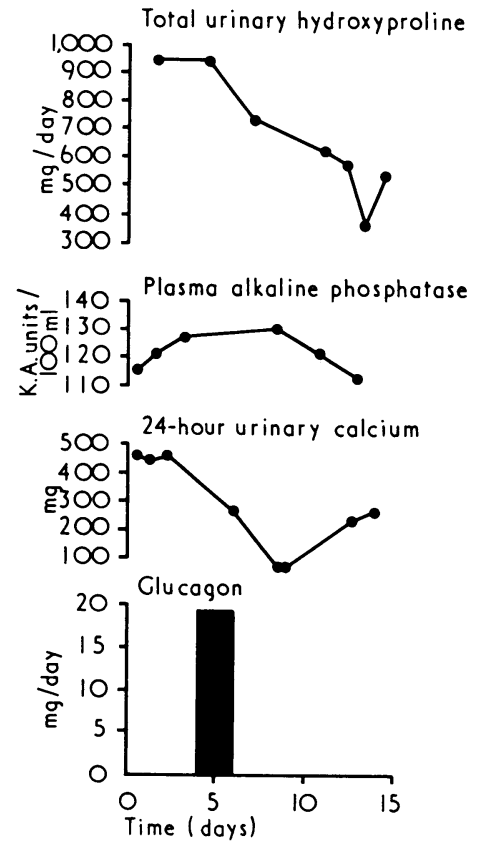

FIG. 3-Case 3. Results of glucagon therapy.
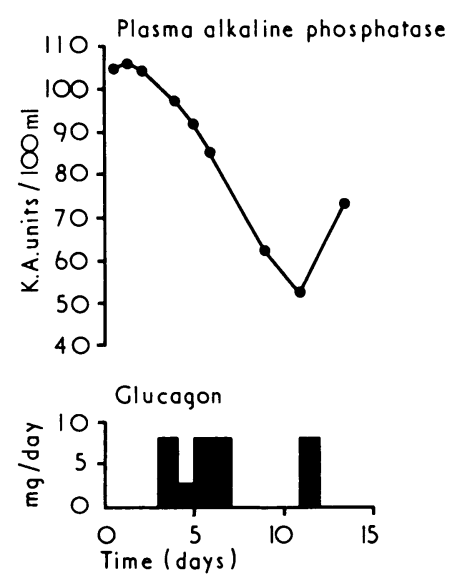

FIG. 4-Case 4. Plasma alkaline phosphatase during treatment.
18 days of starting glucagon therapy (Fig. 2). Total urinary hydroxyproline and urinary calcium also fell sharply. Plasma phosphate fell to $2.3 \mathrm{mg} / 100 \mathrm{ml}$ during glucagon therapy but the plasma calcium remained within normal limits. Calcitonin was not detected in blood samples taken before and at 15, 30, and 240 minutes after starting glucagon.

Marked relief of bone pain occurred six days after beginning glucagon therapy. Unfortunately, it was not possible to follow this patient's weekly progress, but plasma alkaline phosphatase values six weeks after stopping glucagon rose to 110 K.A. units $/ 100 \mathrm{ml}$ and bone pain returned six weeks after stopping glucagon.

\section{Case 3}

A 60-year-old man with Paget's disease of bone was treated with glucagon 24 days after presenting with a fracture of the shaft of his right femur. He had no bone pain at the time of treatment and had been mobilized for two weeks. The 24-hour urinary calcium and total urinary hydroxyproline fell after two days' therapy with glucagon $20 \mathrm{mg} /$ day (Fig. 3). The plasma alkaline phosphatase, which seemed to be rising when therapy was begun, also fell. Unfortunately, the relatively large dose of glucagon given induced nausea and the patient refused further treatment. Plasma calcium remained within normal limits but plasma phosphate fell to $3.1 \mathrm{mg} /$ $100 \mathrm{ml}$ during glucagon therapy.

\section{Case 4}

An 81-year-old man had been known to have radiological evidence of Paget's disease of bone for 11 years. Bone deformities had been noticed for five years but there had been no pain. Intermittent glucagon therapy resulted in a fall in plasma alkaline phosphatase from over 100 to $50 \mathrm{~K}$.A. units $/ 100 \mathrm{ml}$ during a period of nine days (Fig. 4). Unfortunately, it was impossible to collect accurate 24-hour urine specimens. Plasma calcium remained within normal limits but intermittent hypophosphataemia was noted during glucagon infusion.

\section{Discussion}

Glucagon given to patients with Paget's disease of bone resulted in a pronounced and rapid fall in plasma alkaline phosphatase
(Cases 1, 2, 3, and 4). This was accompanied by a fall in urinary calcium (Cases 1, 2, and 3), and marked relief of bone pain (Cases 1 and 2). A fall in total urinary hydroxyproline also occurred during treatment with glucagon and suggests a reduction in the rate of bone turnover.

The mechanism by which glucagon induces these changes is not clear but there are a number of possibilities. The first of these is that glucagon stimulates release of calcitonin, which inhibits resorption of bone (Friedman and Raisz, 1965; Foster, 1968; Reynolds, 1968). Since the report of the hypocalcaemic effect of glucagon in human subjects (Paloyan et al., 1967) Avioli et al. (1968) presented evidence which suggested that glucagon lowered plasma calcium by stimulating release of calcitonin. Further evidence in support of this concept is provided by Care et al. (1970b), who found that glucagon stimulated release of calcitonin from the thyroid gland of the experimental animal.

A number of features indicate that stimulation of release of calcitonin by glucagon may not be the major factor responsible for the metabolic effects observed in Paget's disease. Using a radioimmunoassay technique for human calcitonin (sensitive to quantities greater than $500 \mathrm{pg} / \mathrm{ml}$ ), calcitonin was undetectable on six separate occasions in the plasma of Cases 1 and 2 while they were receiving glucagon. Furthermore, the plasma alkaline phosphatase falls sharply within days of starting glucagon therapy, whereas after human synthetic calcitonin the plasma alkaline phosphatase decreases slowly over many months (Woodhouse et al., 1971). The equivalent doses of glucagon and calcitonin exerting the "same" biological activity on bone are unknown, so that a comparison of rates of fall of plasma alkaline phosphatase with glucagon and human synthetic calcitonin is difficult. Different routes of administration of the hormones may also account for some differences in the rate of response to the two drugs. Nevertheless, on the available evidence glucagon therapy results in a fall of plasma alkaline phosphatase which is about 30 times as rapid as with human calcitonin.

The second possibility to account for the action of glucagon in Paget's disease is a direct action of the hormone itself on bone. Evidence to support this possibility was reported by Stern and Bell (1970), who showed that glucagon could inhibit 
parathyroid-hormone-stimulated bone resorption by a direct effect on the bone of intact and thyroparathyroidectomized rats. The experiments of Tanzer et al. (1970), using radiophosphorus labels in rats, also support the concept of a direct action of glucagon on bone. Glucagon may, therefore, have a similar action to mithramycin in Paget's disease-namely, inhibiting resorption while still allowing the anabolic effect of parathyroid hormone on bone to continue (Condon et al., 1971).

The third possible mode of action of glucagon on bone is more speculative. A large number of enzymes have been found to increase after glucagon therapy, and one of these, glucose-6-phosphatase (Langdon and Weakley, 1955), is an acid phosphatase that has also been shown to be a pyrophosphatase (Nordlie and Arion, 1964; Stetten and Taft, 1964; Nordlie, 1965). Bone contains a number of pyrophosphatases, some of which may be involved in bone resorption (Russell and Fleisch, 1970). Fleisch and his co-workers have proposed that pyrophosphate, an inhibitor of calcification, binds to apatite and inhibits its formation (Fleisch et al., 1966a) as well as its dissolution (Fleisch et al., 1966b). Pyrophosphatases catalyse the hydrolysis of pyrophosphate and by destroying the pyrophosphate locally allows calcium to be either deposited or resorbed. The rate of bone formation and resorption are probably finely balanced by means of an unidentified mechanism (Harris and Heaney, 1969), which may involve pyrophosphate and a number of pyrophosphatases. Stimulation of certain pyrophosphatases by glucagon may in some way affect the local mechanisms controlling the rate of bone formation and resorption and account for the clinical and biochemical changes induced by glucagon.

If this last explanation is correct glucagon may prove to be useful in investigating the role of different pyrophosphatases in normal and pathological bone metabolism, and this may eventually lead to a clearer understanding of the aetiology of a number of bone disorders.

I am grateful to Dr. J. Jenkins, Dr. J. Nixon, Mr. Bendall, and Dr. J. Batten for their permission to report Cases 1, 2, 3, and 4.
I am also indebted to Dr. G. V. Foster and Dr. M. B. Clark for the calcitonin assays and to Professor J. A. Owen and Dr. P. Maitland and staff of the department of chemical pathology for their help. I would also like to thank Eli Lilli Ltd. for their generous assistance.

\section{References}

Avioli, L. V., Birge, S. J., Kanagawa, H., and Shieber, W. (1968). fournal Clinical Investigation, 47, 3a.

Bijvoet, O. L. M., van der Sluys Veer, J., and Jansen, A. P. (1968). Lancet, $1,876$.

Care, A. D., Bates, R. F. L., and Gitelman, H. J. (1970a). Fournal of Endocrinology, 48, 1 .

Care, A. D., et al. (1970b). Fournal of Endocrinology, 48, 667.

Clark, M. B., Boyd, G. W., Byfield, P. G. H., and Foster, G. V. (1969). Lancet, $2,74$.

Condon, J. R., et al. (1971). British Medical fournal, 1, 421.

Fleisch, H., Maerki, J., and Russell, R. G. G. (1966a). Proceedings of the Society for Experimental Biology and Medicine, 122, 317.

Fleisch, H., Russell, R. G. G., and Straumann, F. (1966b). Nature, 212, 901 .

Foster, G. V. (1968). New England fournal of Medicine, 279, 349.

Friedman, J., and Raisz, L. G. (1965). Science, 150, 1465.

Gehrke, C. W., Affprung, H. E., and Lee, Y. C. (1954). Analytical Chemistry, 26, 1944. (1964). Fournal of Clinical Pathology, 7, 685.

Grant, R. A. (1964). Fournal of Clinical Pathology, 7, 685.
Harris, W. H., and Heaney, R. P. (1969). New England fournal of Medicine, Harris, W. H., and Hea

Kind, P. R. N., and King, E. J. (1954). Fournal of Clinical Pathology, 7, 322 .

Kraml, M. (1966). Clinica Chimica Acta, 13, 442.

Langdon, R. G., and Weakley, D. R. (1955). fournal of Biological Chemistry, 214, 167.

MacIntyre, I. (1960). Advances in Clinical Chemistry, 4, 1.

Nordlie, R. C. (1965). Fournal of Biological Chemistry, 240, 2155.

Nordlie, R. C., and Arion, W. J. (1964). Fournal of Biological Chemistry, 239, 1680.

Paloyan, E., Paloyan, D., and Harper, P. V. (1967). Metabolism, 16, 35.

Pennock, C. A., Moore, G. R., and Hoyle, M. D. (1970). Fournal of Medical Laboratory Technology, 27, 302

Laboratory Technology, 27, 302 .
Reynolds, J. J. (1968). Proceedings of the Royal Society, B170, 61.

Russell, R. G. G., and Fleisch, H. (1970). Clinical Orthopaedics and Related Research, 69, 101.

Stern, P. H., and Bell, N. H. (1970). Endocrinology, 87, 111.

Stetten, M. R., and Taft, H. L. (1964). Fournal of Biological Chemistry, $239,4041$.

Tanzer, F. S., Kennedy, J. W., and Talmage, R. V. (1970). Proceedings of the Society for Experiemental Biology and Medicine, 133, 500.

Woodhouse, N. J. Y., et al. (1971). Lancet, 1, 1139.

\section{PRELIMINARY COMMUNICATIONS}

\section{Unusual Particles in Splenic Disorders}

\author{
A. E. STUART, A. I. S. MACPHERSON, \\ J. RICHMOND
}

British Medical fournal, 1971, 4, 721-722

\section{Summary}

Virus-like particles have been seen on electronmicroscopic examination of four spleens surgically removed for haematological disorders-three cases of idiopathic thrombocyto-

University of Edinburgh Medical School, Edinburgh

A. E. STUART, F.R.C.P.ED, PH.D., Reader in Pathology

J. RICHMOND, M.D., F.R.C.P.ED., Reader in Medicine

Royal Infirmary, Edinburgh EH3 9YW

A. I. S. MACPHERSON, CH.M., F.R.C.S.ED., F.R.S.ED., Consultant Surgeon penic purpura and one case of haemolytic anaemia. The particles were approximately spherical and 50-60 nanometres in diameter.

During the course of electron microscopic examination of surgically resected human spleens, virus-like particles were seen in three cases of idiopathic thrombocytopenic purpura and in one case of haemolytic anaemia of obscure origin. Our material was derived from nine patients-single cases of congenital spherocytosis, haemolytic anaemia, myelofibrosis, and disseminated lupus erythematosus associated with thrombocytopenia, and three cases of idiopathic thrombocytopenic purpura. Two normal spleens were also examined. The clinical histories of four patients are summarized.

\section{Case Reports}

Case 1.-Man aged 22. Sudden onset of spontaneous bleeding, purpura, and ecchymosis. No history of drugs or recent illness. Spleen not palpable. Haemoglobin $15 \mathrm{~g} / 100 \mathrm{ml}$, platelets under $10,000 / \mathrm{mm}^{3}$, W.B.C. $6,400 / \mathrm{mm}^{3}$, differential count normal. Marrow showed numerous megakaryocytes. Idiopathic thrombocytopenic 